\title{
Pressure Control Technology at the Hard Thick Sandstone Roof in an Island Mining Face with a Large Mining Height
}

\author{
Baojie FU*, Min TU, Qingchong ZHAO
}

\begin{abstract}
Fracture of a critical stratum on a coal seam roof may cause strong strata pressure behaviours. In particular, a large-scale sudden fracture of the critical stratum, which is formed by hard thick sandstones on a mining face with a large mining height, can easily cause dynamic disasters of wells. In this study, a simulation analysis of the deformation and failure laws of a hard thick roof in an island mining face with a large mining height in Xinji 2\# Mine 210106 after the mining of Coal bed A1 was performed in accordance with the occurrence characteristics of sandstones. Results demonstrate that large-scale fracture suddenly occurs at a gob roof after the working face is advanced by $120 \mathrm{~m}$. A mechanical analysis model of the island working face was constructed. This model comprises $17.9 \mathrm{~m}$ of fracture on the $16 \mathrm{~m}$ thick sandstone roof. Hydraulic support provides $16854.1 \mathrm{kN}$ of supporting resistance to maintain the stability of the rock beam and thus prevent threats to the supporting devices of the working face. The hard thick roof was weakened every $15 \mathrm{~m}$ in the transport gateway and air return in advance through an advanced deep-hole pre-splitting blasting technique. In accordance with the measurement results of underground pressure, the forced caving of thick sandstones relieves the influence of roof loads on the support and thus realizes safe mining.
\end{abstract}

Keywords: critical hard thick stratum; large mining height; pre-splitting blasting; roof control

\section{INTRODUCTION}

Given the differences in diagenesis, mineral components, and geological structure of the strata of coal systems, the thickness and mechanical properties of different rock strata may differ slightly [1]. During the mining of coal beds with a large mining height, the fracture of a thick hard stratum on the coal roof at a close distance can easily produce rock burst, thereby causing serious dynamic mine disasters. Therefore, analyzing the stress distribution law on surrounding rocks at a hard thick roof of a coal bed with a large mining height and the corresponding structural characteristics, predicting the dangerous zone on the working face, and adopting prepressure relief measures in accordance with the supporting capacity of supporting devices [2-7] are important methods for ensuring the safety of the working face. Currently, associated studies have mainly focused on the movement laws of the overlying strata in the stope [8-13]. Few studies have discussed the relationship between the supporting resistance and the roof weighting step of the supporting structure in accordance with the occurrence characteristics of the overlying strata in the coal bed. In the present study, the influences of the fracture of the upper roof on the supporting resistance of the working face were analyzed in accordance with the occurrence conditions of surrounding rocks on the working face in Xinji 2\# Mine 210106. In addition, pre-pressure relief measures were adopted from the perspective of support safety to prevent the compression failure of the support in the stope.

\section{LITHOLOGICAL CONDITIONS OF WORKING FACE}

Coal bed A1 is the main mining face on the working face of Xinji 2\# Mine 210106. The thickness of A1 is 0.1 $5.9 \mathrm{~m}\left(3.5 \mathrm{~m}\right.$ on average), and the coal bed pitch is $5^{\circ}-12^{\circ}$ ( $8^{\circ}$ on average). A1 has a simple and stable structure in the entire region. Fig. 1 illustrates the histogram of the surrounding rocks on the working face. In this coal bed, the roof is formed by a thick sandstone layer, accompanied by siltstone, fine sandstone, moderate fine sandstone, and sand mudstone. Among them, the moderate fine sandstone is the key component, and calcite cementation is predominant. The rock properties $36 \mathrm{~m}$ above the coal bed roof were tested. The compressive strengths of moderate fine sandstone and siltstone were 95 - 134 and 63 - $87 \mathrm{MPa}$, respectively.

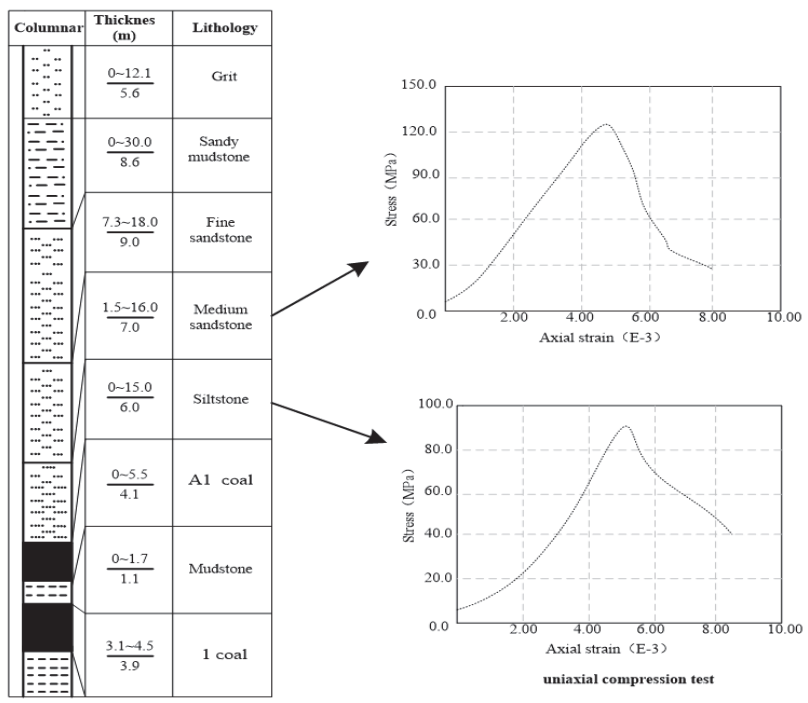

Figure 1 Roof lithology and uniaxial compressive stress-strain curves

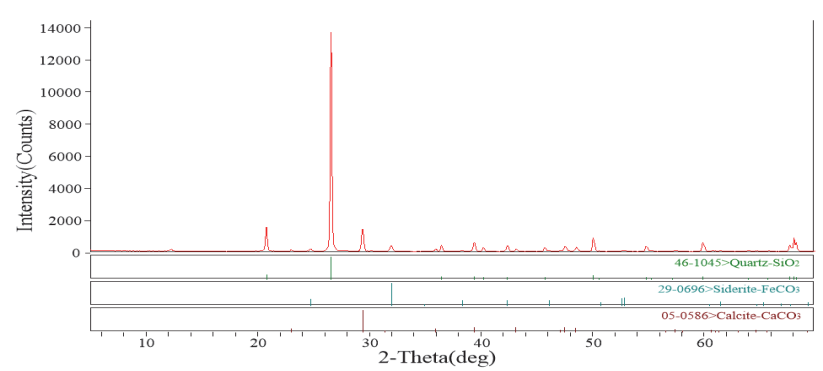

Figure 2 XRD test results chart of fine sandstone

According to the X-Ray Diffraction (XRD) test, the moderate fine sandstone in the roof mainly contains three crystal minerals, namely, quartz $\left(\mathrm{SiO}_{2}\right)$, siderite $\left(\mathrm{FeCO}_{3}\right)$, and calcite $\left(\mathrm{CaCO}_{3}\right)$. According to the calculation, the 
relative percentages of the three crystal minerals are $83.71 \%, 1.45 \%$, and $14.84 \%$, respectively. The results are plotted in Fig. 2.

Fig. 3 demonstrates that the siltstone on the roof mainly contains four crystal minerals, namely, quartz $\left(\mathrm{SiO}_{2}\right)$, siderite $\left(\mathrm{FeCO}_{3}\right)$, kaolinite $\left(\mathrm{Al}_{2} \mathrm{Si}_{2} \mathrm{O}_{5}(\mathrm{OH})_{4}\right)$, and calcite $\left(\mathrm{CaCO}_{3}\right)$. According to the calculation, the relative percentages of the four crystal minerals are $85.86 \%$, $1.06 \%, 4.00 \%$, and $9.08 \%$, respectively.

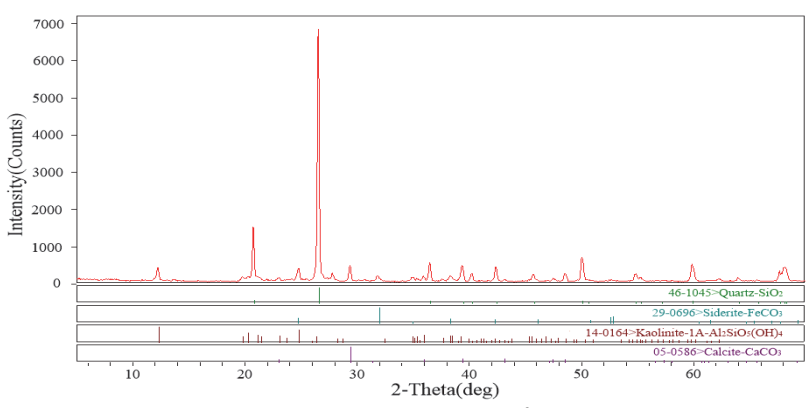

Figure $3 \mathrm{XRD}$ test results chart of siltstone

The 210106 working face has a thick sandstone roof, which has a high quartz content and strong calcite cementation, thereby resulting in the high stability and strength of the roof. Without effective measures, the roof may not fall easily during the mining of the coal bed, and a large area of hanging arch exists. A1 is a coal bed with a high gas content. The large-scale falling off of the roof may cause considerable rock bursts and compressive failure of the supporting structure, thereby further inducing windstorm and gas transfinite.

\section{MOVEMENT DEFORMATION CHARACTERISTICS OF A HARD THICK ROOF}

A numerical calculation model $(800 \mathrm{~m}$ (length) $\times 400$ $\mathrm{m}$ (width) $\times 300 \mathrm{~m}$ (height)) was constructed using FLAC3D to analyze the deformation law of the hard thick roof in the working face with a large mining height, which employed 486,020 zones. In this model, $100 \mathrm{~m}$ coal pillars were left at the boundaries. Moreover, horizontal constraints surrounding the model were used, whereas the bottom boundary was fixed. The upper boundary was a free surface where vertical stress of 7.8 MPa was applied. The entire numerical model is exhibited in Fig. 4,

The movement laws of the overlying strata when island working face 210106 was advanced by different distances were simulated and analyzed after the mining of working faces 210108 and 210104. All working faces were $235 \mathrm{~m}$ long, and the mining height was $3.5 \mathrm{~m}$. The coal pillar was $10 \mathrm{~m}$ high in the region.

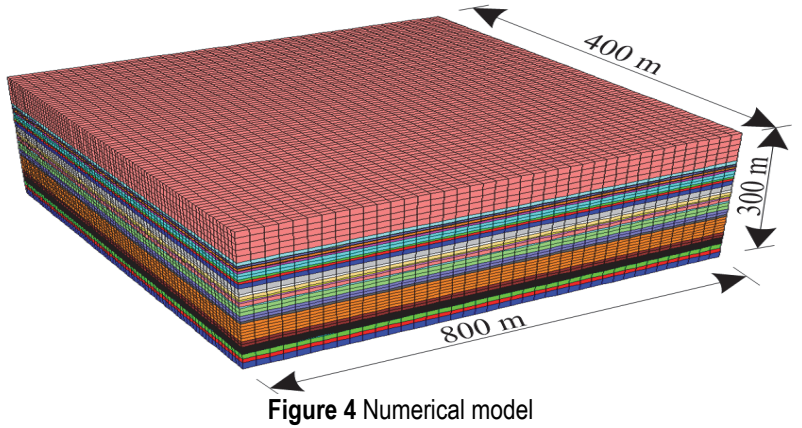

A compound failure criterion of Mohr-Coulomb criterion with tension cutoff was employed for this simulation. Some generic mechanical properties for the rock mass were selected for the model. The mechanical properties were shown in Tab. 1.

Table 1 Material parameters of rock mass

\begin{tabular}{|l|c|c|c|c|c|c|}
\hline & \multicolumn{6}{|c|}{ Material parameters } \\
\cline { 2 - 7 } Lithology & $\begin{array}{c}\text { Young's } \\
\text { modulus } \\
E / \mathrm{GPa}\end{array}$ & $\begin{array}{c}\text { Poisson's } \\
\text { ratio } v\end{array}$ & $\begin{array}{c}\text { Cohesion } \\
C / \mathrm{MPa}\end{array}$ & $\begin{array}{c}\text { Friction } \\
\text { angle } \varphi \\
/ \circ\end{array}$ & $\begin{array}{c}\text { Density } \\
\rho / \\
\mathrm{kgm}^{3}\end{array}$ & $\begin{array}{c}\text { Tensile } \\
\text { strength } \\
\sigma_{\mathrm{t}} / \\
\mathrm{MPa}\end{array}$ \\
\hline $\begin{array}{l}\text { Standy } \\
\text { mudston }\end{array}$ & 6 & 0.27 & 2.16 & 31 & 2615 & 4.22 \\
\hline $\begin{array}{l}\text { Fine } \\
\text { sandstone }\end{array}$ & 11 & 0.21 & 4.45 & 34 & 2687 & 6.75 \\
\hline $\begin{array}{l}\text { Medium } \\
\text { sandstone }\end{array}$ & 13 & 0.22 & 4.76 & 35 & 2643 & 7.02 \\
\hline Silltstone & 6 & 0.34 & 1.38 & 30 & 2634 & 4.56 \\
\hline
\end{tabular}

The subsidence displacement cloud map of the roof is displayed in Fig. 5. The overlying strata sunk, and the bottom roof developed a slight swelling after the mining of the coal bed. The sphere of influence of mining on the deformation of the overlying strata was approximately 60 $\mathrm{m}$ when the working face was advanced by $40 \mathrm{~m}$. It increased to nearly $100 \mathrm{~m}$ when the working face was advanced by $80 \mathrm{~m}$. Moreover, the overlying strata began to sink significantly when the working face was advanced by $120 \mathrm{~m}$, and the maximum subsidence value reached $3.5 \mathrm{~m}$ when the working face was advanced by $160 \mathrm{~m}$.

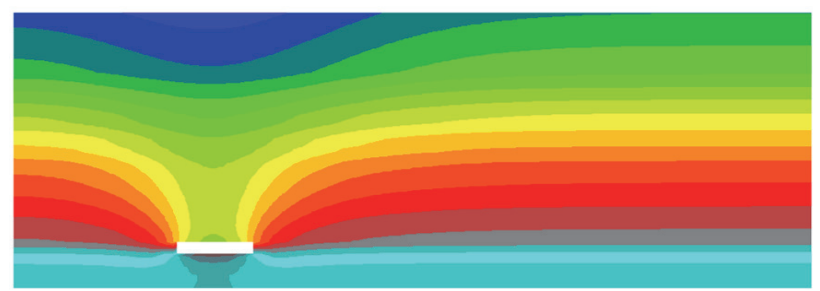

(a) Working face is advanced by $40 \mathrm{~m}$

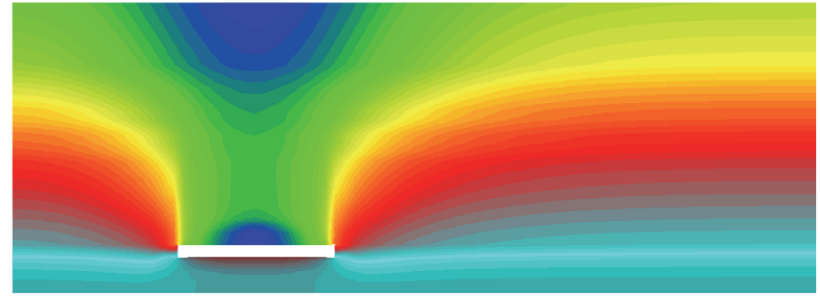

(b) Working face is advanced by $80 \mathrm{~m}$

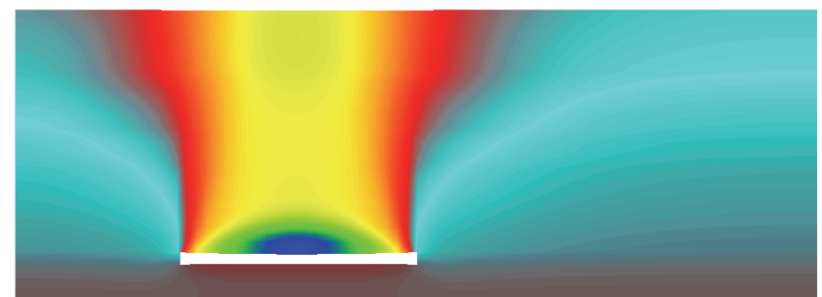

(c) Working face is advanced by $120 \mathrm{~m}$

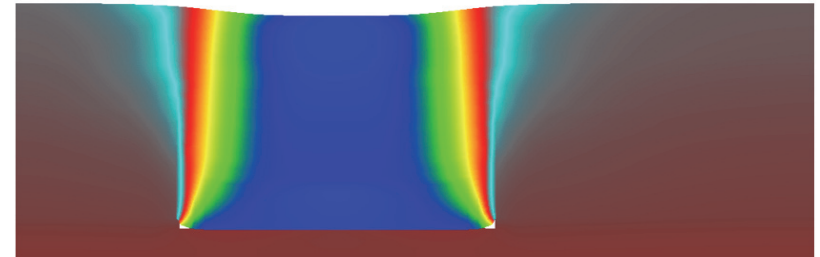

(d) Working face is advanced by $160 \mathrm{~m}$ Figure 5 Vertical displacement cloud map 
The subsidence curves of the overlying strata at $30 \mathrm{~m}$ of the coal bed roof are plotted in Fig. 6. Influenced by the hard thick roof, the overlying strata did not develop sufficient subsidence displacement when the working face was advanced by $120 \mathrm{~m}$. Subsequently, the strata at the measuring line fell completely, and the maximum subsidence was equal to the mining thickness that reaches $3.5 \mathrm{~m}$.

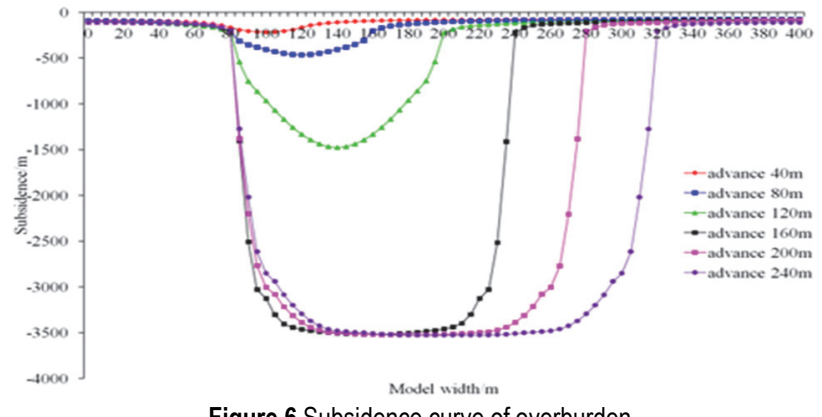

Figure 6 Subsidence curve of overburden

\section{CONSTRUCTION AND ANALYSIS OF A MECHANICAL MODEL OF THE ISLAND WORKING FACE}

\subsection{Thin-plate Fracture Analysis}

In accordance with the positional relation of the stope on the island working face, the $16 \mathrm{~m}$ thick moderate-fine sandstone roof on stope face 210106 was viewed in this study as a rectangular thin plate, because the ratio of thickness to face length is between 0.01 and 0.2 . The entry protection coal pillars at two sides of the working face and the rear position of the working face were viewed as the simply supported boundary conditions of a thin plate. One side was a clamp-supported "C-shaped" island stope face model. Namely, three sides were simply supported and one side was fixed, and the size of the thin plate was $a$ (length) $\times b$ (width). The model is illustrated in Fig. 7 .

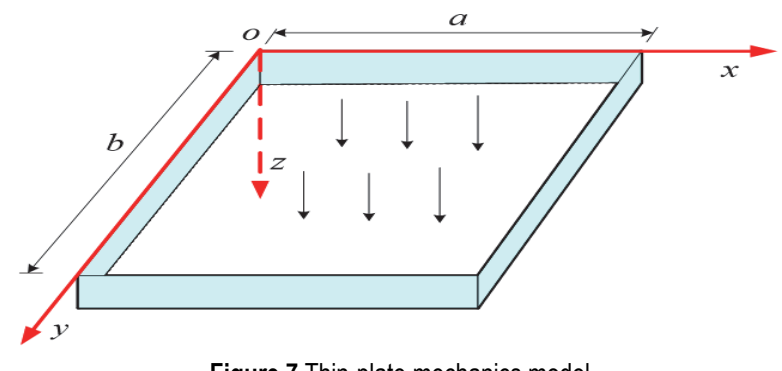

Figure 7 Thin-plate mechanics model

Given that the overlying strata were simplified into uniformly distributed loads with an intensity of $q$, the subsidence deflection of the roof can be expressed as:

$w=C\left(\frac{x}{a}\right)^{2} \sin \left(\frac{\pi y}{b}\right)$

where: $C$ is a coefficient.

Eq. (1) is introduced into the deformation energy function of the thin plate.

$U=\frac{C^{2} D q\left(60 b^{4}+3 a^{4} \pi^{4}+40 a^{2} \pi^{2} b^{2}-60 a^{2} \pi^{2} b^{2} \mu\right)}{60 a^{3} b^{3}}$ where: the bending rigidity of a roof is $D=\frac{E \delta^{3}}{12\left(1-\mu^{2}\right)}$,

where: $a$ and $b$ are the length and width of the thin plate, correspondingly. $q$ is the load of the overlying strata in the basic roof. $\delta$ is the thickness of the strata on the roof. $\mu$ is the Poisson's ratio of the strata on the roof. $E$ is the modulus of elasticity of the strata on the roof.

According to the Rayleigh-Ritz method and the minimum energy principle:

$$
C=\frac{20 a^{4} b^{4} q}{\pi D\left(60 b^{4}+3 a^{4} \pi^{4}+40 a^{2} \pi^{2} b^{2}-60 a^{2} \pi^{2} b^{2} \mu\right)}
$$

Eq. (3) is introduced into Eq. (2), such that the bending-induced strain energy of a plate with a simple support at three sides and a fixed support at one side can be derived as follows:

$$
U=\frac{80 a^{5} b^{5} q^{2}\left(1-\mu^{2}\right)}{\pi^{2} E \delta^{3}\left(60 b^{4}+3 a^{4} \pi^{4}+40 a^{2} \pi^{2} b^{2}-60 a^{2} \pi^{2} b^{2} \mu\right)}
$$

Based on the deformation conversion of the principal stress components:

$$
\begin{aligned}
& \sigma_{x}=\frac{E z}{1-\mu^{2}}\left(\frac{20 a^{2} b^{2} q \sin \left(\frac{\pi y}{b}\right)\left(2 b^{2}-\mu \pi^{2} x^{2}\right)}{\pi D\left(60 b^{4}+3 a^{4} \pi^{4}+40 a^{2} \pi^{2} b^{2}-60 a^{2} \pi^{2} b^{2} \mu\right)}\right) \\
& \sigma_{y}=\frac{E z}{1-\mu^{2}}\left(\frac{20 a^{2} b^{2} q \sin \left(\frac{\pi y}{b}\right)\left(2 \mu b^{2}-\pi^{2} x^{2}\right)}{\pi D\left(60 b^{4}+3 a^{4} \pi^{4}+40 a^{2} \pi^{2} b^{2}-60 a^{2} \pi^{2} b^{2} \mu\right)}\right) \\
& \tau_{x y}=\frac{E z}{1+\mu}\left(\frac{20 a^{2} b^{2} q \pi x^{2} \sin \left(\frac{\pi y}{b}\right)}{D\left(60 b^{4}+3 a^{4} \pi^{4}+40 a^{2} \pi^{2} b^{2}-60 a^{2} \pi^{2} b^{2} \mu\right)}\right)
\end{aligned}
$$

When: $x=0, y=\frac{b}{2}$, the horizontal stress is the maximum tensile stress.

$$
\sigma_{t}=-\frac{E z}{1-\mu^{2}}\left(\frac{40 b^{2} q}{\pi D\left(60 \frac{b^{2}}{a^{2}}+3 \frac{b^{2}}{a^{2}} \pi^{4}+40 \pi^{2}-60 \pi^{2} \mu\right)}\right)
$$

In accordance with the geographical conditions and mining technological conditions of the working face, the values of relevant parameters can be determined as follows: $a=235$ $\mathrm{m}, \delta=16 \mathrm{~m}, E=8.7 \mathrm{GPa}, \mu=0.4, Z=8 \mathrm{~m}, \sigma_{\mathrm{t}}=1.2 \mathrm{Mpa}$ and $q=2.0 \mathrm{MPa}$

Therefore, $b=17.9 \mathrm{~m}$. In particular, the fracture distance on the $16 \mathrm{~m}$ thick sandstone roof was calculated as $17.9 \mathrm{~m}$.

\subsection{Structural Stability Analysis of the Overlying Strata}

Given certain deformations, the key pieces of the roof break and form a hinged structure. Considering the high 
thickness and excessive fracture distance of the critical layer, Key piece B accomplishes a rotation and stabilizes at the fracture of Key piece A. Therefore, the additional force to maintain the equilibrium of Key piece $\mathrm{B}$ in the hinged structure composed of Key pieces A, B, and C is the highest when the support is in the position depicted in Fig. 8. The additional force $\left(Q_{p 1}\right)$ can be expressed as:

$Q_{p 1}=\left[Q-\frac{l Q \tan (\phi-\theta)}{2(h-\Delta)}\right] B$,

where: $B$ is the width of the support. $\varphi$ is the frictional angle among different rock pieces. $\theta$ is the fracture angle of the rock pieces. $Q$ is the load of Key piece $\mathrm{B}$ and the overlying strata.

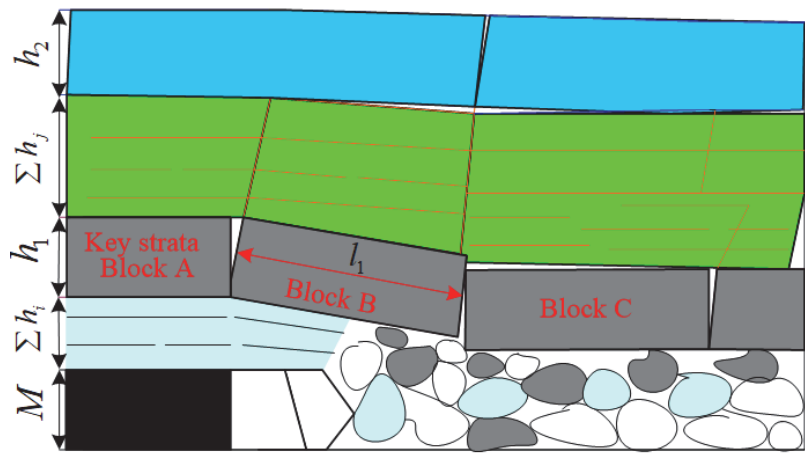

Figure 8 Spatial structure model of a roof

Under this circumstance, the loads of the working support are composed of the weight $\left(Q_{z}\right)$ of the direct roof below the critical layer and the balance force $\left(Q_{p 1}\right)$ required by the hinged structure of Key piece B.

$P=Q_{z}+Q_{p 1}=B l_{k} \sum h_{i} \gamma+\left[1-\frac{l_{1} \tan \left(\phi_{1}-\theta_{1}\right)}{2\left(h_{1}-\Delta\right)}\right] Q_{1} B$,

where: $l_{k}$ is the distance between the support structure and the roof. $Q_{1}$ is the load of Key piece B and the overlying strata. Several parameters are known: $B=1.75 \mathrm{~m}, l_{k}=7.0$ $\mathrm{m}, \Sigma h_{i}=30.9 \mathrm{~m}, \gamma=2.6 \times 10^{3} \mathrm{~kg} / \mathrm{m}^{3}, l_{1}=17.9 \mathrm{~m}, \tan \left(\varphi_{1}-\right.$ $\left.\theta_{1}\right)=0.7, h_{1}=16.1 \mathrm{~m}, \Delta=3.5 \mathrm{~m}$, and supporting resistance $P=16854.1 \mathrm{kN}$. The support mode of the working face is ZZ15000/24/50D. Therefore, the maximum working resistance of $15000 \mathrm{kN}$ cannot satisfy the requirements of a normal supporting roof. Therefore, the $16 \mathrm{~m}$ thick sandstone roof applies advanced pre-splitting blasting technology [14-17], and the fracture distance is $15 \mathrm{~m}$.

\section{ADVANCED PRE-SPLITTING BLASTING CONTROLLED ROOF}

To prevent a dynamic impact of roof fracture on the support of the working face, a pre-splitting blasting of the $16 \mathrm{~m}$ thick hard fine sandstone roof was performed using advanced pre-splitting blasting technology. Considering the fixed supports at the four sides of the stope roof in early mining, the first blasting position was at $30 \mathrm{~m}$ in front of the cutting hole. Under periodic weighting, one group of shot holes (four holes in each group) was formed every 15 $\mathrm{m}$ in the upper and lower air return ways on each working face. The parameters are listed in Tab. 2. The distribution of shot holes is presented in Fig. 9.

\begin{tabular}{|c|c|c|c|c|c|c|c|}
\hline Roadway & Serial number & Depth / m & Angle $/{ }^{\circ}$ & Horizontal Angle / ${ }^{\circ}$ & Diameter / mm & Charging length / m & Block length / m \\
\hline \multirow{4}{*}{$\begin{array}{c}\text { Transportation } \\
\text { lane }\end{array}$} & $1 \#$ & 111 & 17 & 0 & 94 & 69 & 42 \\
\hline & $2 \#$ & 81 & 20 & 0 & 94 & 50 & 31 \\
\hline & $3 \#$ & 52 & 26 & 0 & 94 & 32 & 20 \\
\hline & $4 \#$ & 24 & 53 & 0 & 94 & 15 & 9 \\
\hline \multirow{4}{*}{ Return air lane } & $1 \#$ & 111 & 1 & 0 & 94 & 69 & 42 \\
\hline & $2 \#$ & 81 & 4 & 0 & 94 & 50 & 31 \\
\hline & $3 \#$ & 52 & 10 & 0 & 94 & 32 & 20 \\
\hline & $4 \#$ & 24 & 27 & 0 & 94 & 15 & 9 \\
\hline
\end{tabular}
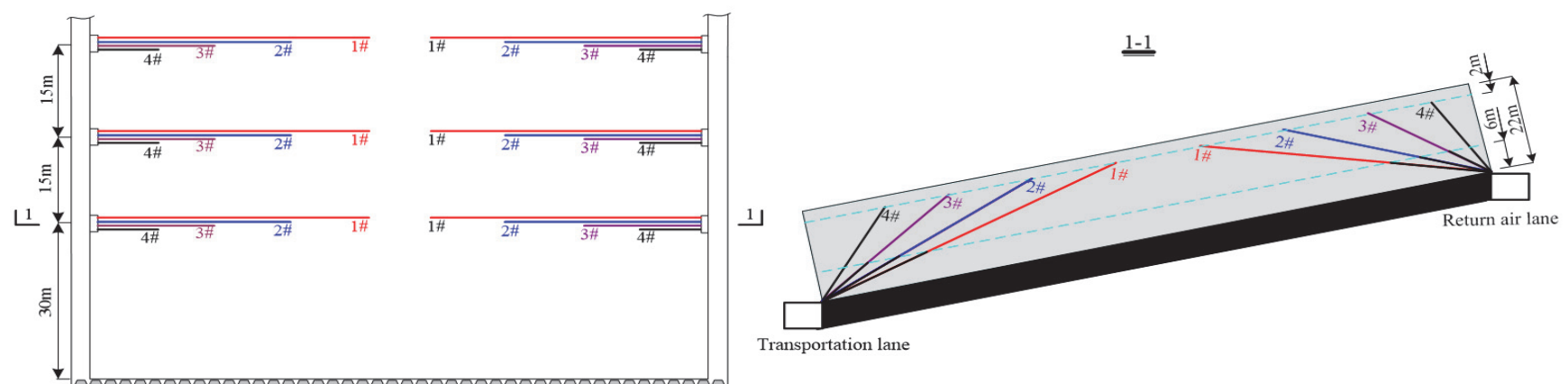

210106 working face

Figure 9 Perforation plan 
One-way long wall fully mechanized backward mining technique was applied to working face 210106, and the roof was managed through the full collapse method. Fullseam mining was implemented, and the average mining height was $3.5 \mathrm{~m}$. A total of $1254000 \mathrm{t}$ of commercial coals were produced.

\section{STRATA PRESSURE BEHAVIOR CHARACTERISTICS OF THE WORKING FACE}

The working resistance of the hydraulic support was tested using a KJ345 hydraulic support monitoring system of coal mines. A total of 7 measuring lines were set on the entire working face, and 14 pressure machines were installed. These machines were $5 \#, 15 \#, 25 \#, 35 \#, 45 \#$, 55\#, 65\#, 75\#, 85\#, 95\#, 105\#, 115\#, 125\#, and 135\# supports.

\subsection{First Weighting}

The sum of the average cyclic terminal resistance $(P)$ of the supports and the mean square error $(\sigma)$ were used as the main indexes to judge the roof weighting in the weighting analysis of the basic roof. Furthermore, this pressure was maintained for a certain period. Fig. 10 displays that the pressure thresholds on the upper, middle, and lower positions of the working face during the first weighting are $33.1,35.6$, and $31.7 \mathrm{MPa}$, respectively. The fracture distances of the corresponding distances were $33.2,30.4$, and $31.2 \mathrm{~m}$. The average step in the first weighting was $31.6 \mathrm{~m}$, and the average lasting distance of weighting was $2.8 \mathrm{~m}$. The average cyclic terminal resistance on the upper position of the working face was $11014 \mathrm{kN}$, which is $73 \%$ of the rated working resistance. The maximum cyclic terminal resistance was $13851 \mathrm{kN}$, which is $92 \%$ of the rated working resistance. The average cyclic terminal resistance in the middle of the working face was $11524 \mathrm{kN}$ ( $77 \%$ of the rated working resistance), and the maximum cyclic terminal resistance was $14960 \mathrm{kN}$ ( $99 \%$ of the rated working resistance). The average cyclic terminal resistance in the lower position of the working face was $10037 \mathrm{kN}$ (67\% of the rated working resistance), and the maximum cyclic terminal resistance is $13321 \mathrm{kN}$ ( $88 \%$ of the rated working resistance). In summary, the maximum terminal resistance was achieved in the middle of the working face, followed by those at the upper and lower positions of the working face.

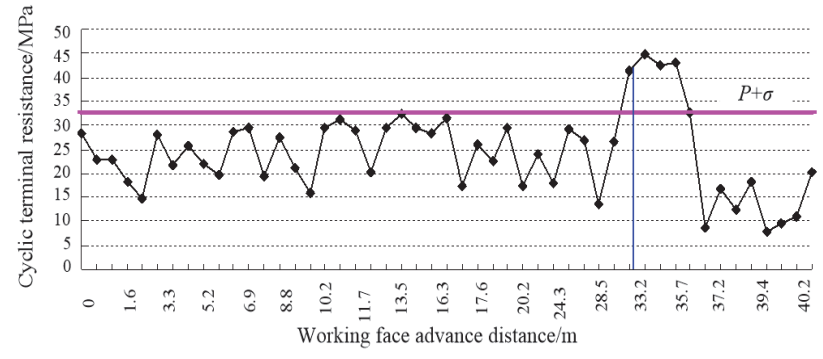

(a) Upper pressure curve of the working face

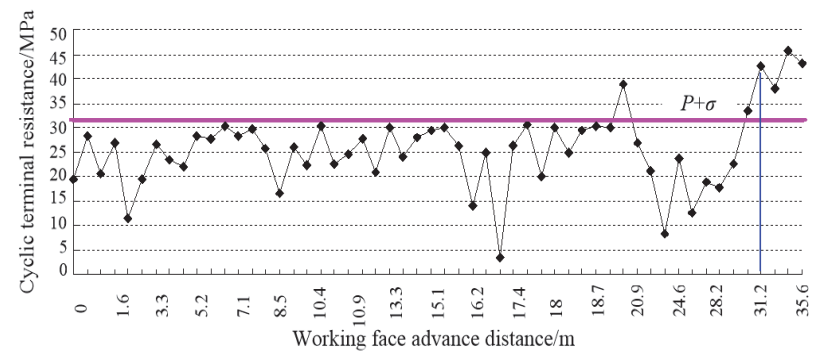

(c) Lower pressure curve of the working face

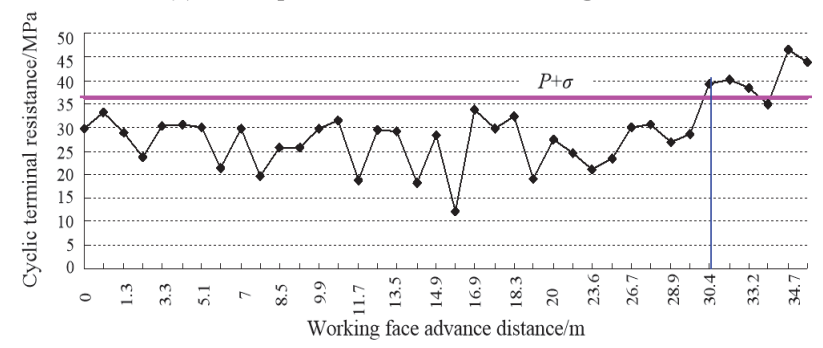

(b) Middle pressure curve of the working face

Figure 10 Pressure curves of the support during the initial pressure

Tab. 3 summarizes that the weighting intensity of the entire working face is ordinary. The dynamic factors at the upper position of the working face were $1.27-1.46(1.36$ on average). The dynamic factors in the middle of the working face were $1.25-1.48$ (1.38 on average). The dynamic factors at the lower position of the working face were 1.28 - 1.41(1.35 on average). The dynamic load indicated that the dynamic pressure on the entire working face is not evident. This result is related to the complete failure of the overlying strata of the roof and the timely filling of the gob. The allowable rotating deformation was very small when the upper roof was fractured completely. Most energy in the rotating process was absorbed by the broken gauges, thus resulting in insignificant pressure on the hydraulic support.

Table 3 Statistics of support resistance before and after the first pressure

\begin{tabular}{|c|c|c|c|c|c|c|c|}
\hline \multicolumn{2}{|c|}{ Position of pressure } & $\begin{array}{l}\text { Upper 15\# } \\
\text { / kN }\end{array}$ & $\begin{array}{l}\text { Upper 25\# } \\
\text { / kN }\end{array}$ & $\begin{array}{l}\text { Middle 65\# } \\
\text { / kN }\end{array}$ & $\begin{array}{l}\text { Middle 75\# } \\
/ \mathrm{kN}\end{array}$ & $\begin{array}{c}\text { Lower 135\# } \\
/ \mathrm{kN}\end{array}$ & $\begin{array}{c}\text { Lower 145\# } \\
/ \mathrm{kN}\end{array}$ \\
\hline \multirow{2}{*}{ First pressure } & Before & 10575 & 10068 & 10622 & 10472 & 9525 & 9693 \\
\hline & After & 15338 & 14443 & 15665 & 15424 & 13592 & 13729 \\
\hline
\end{tabular}

\subsection{Periodic Weighting}

In Fig. 11, the pressure threshold at the upper, middle, and lower positions of the working face during periodic weighting was approximately $40 \mathrm{MPa}$. The weighting steps on the coal bed and roof strata on the working face were generally consistent. This finding was attributed to a stable occurrence. The average and maximum cyclic terminal resistances on the upper position of the working face were 9680 and $12951 \mathrm{kN}$, which are $65 \%$ and $86 \%$ of the rated working resistance, respectively. The average and maximum cyclic terminal resistances on the middle position of the working face were 9991 and $13567 \mathrm{kN}$. These values were $67 \%$ and $90 \%$ of the rated working resistance, respectively. The average and maximum cyclic terminal resistances on the upper position of the working face are 9112 and $12507 \mathrm{kN}$, which are $61 \%$ and $83 \%$ of the rated working resistance, respectively. In summary, the maximum terminal resistance was in the middle of the working face, followed by those on the upper and lower 
positions of the working face. The periodic weighting steps were $13.6-16.8 \mathrm{~m}$ (15.2 $\mathrm{m}$ on average).

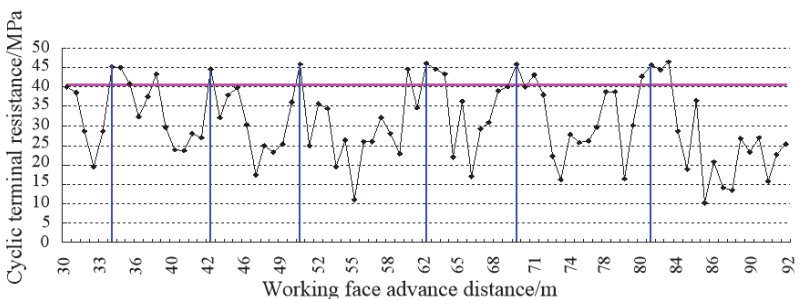

(a) Upper pressure curve of the working face

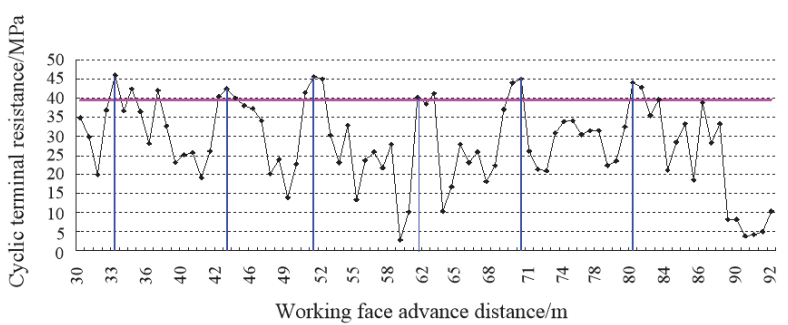

(b) Middle pressure curve of the working face

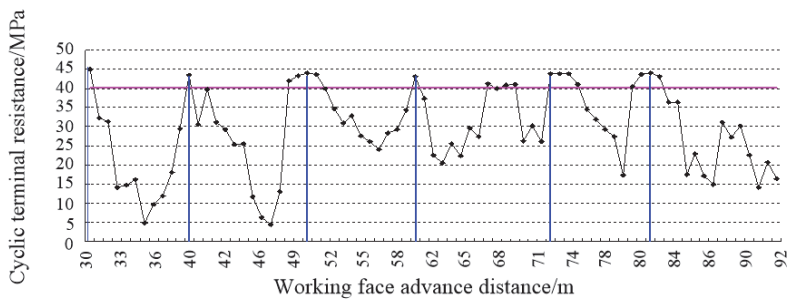

(c) Lower pressure curve of the working face

Figure 11 Pressure curves during the period of pressure
With respect to the working terminal resistance of the support before and after the periodic weighting of the upper roof, the resistance range of the support before periodic weighting was 7454.8 - $13045.8 \mathrm{kN}(9759.4 \mathrm{kN}$ on average). The resistance range of the support during the periodic weighting was 9545.8 - $15666.6 \mathrm{kN}$ (12689 kN on average). The dynamic factor of weighting ranged from 1.22 to 1.40 (1.31 on average). Specifically, the dynamic factors of weighting on the upper, middle, and lower positions of the working face were $1.31,1.34$, and 1.29, correspondingly. This result reflected that the maximum dynamic factor is in the middle of the working face, followed by those in the upper and lower positions. The entire pressure distribution along the working face is presented in Fig. 12.

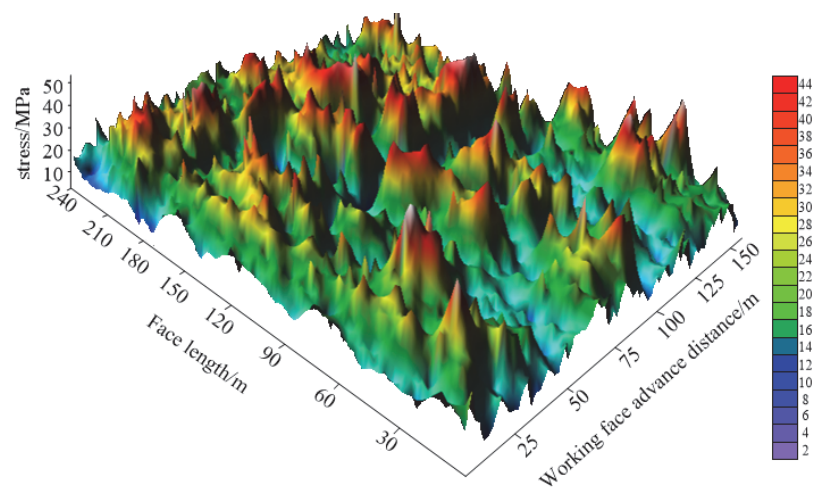

Figure 12 Working face pressure distribution

Table 4 Statistics of the support resistance in the period before and after the cycle

\begin{tabular}{|c|c|c|c|c|c|c|c|c|}
\hline \multicolumn{3}{|c|}{ Position of pressure } & $\begin{array}{c}\text { Upper } \\
15 \#\end{array}$ & $\begin{array}{l}\text { Upper } \\
25 \#\end{array}$ & $\begin{array}{c}\text { Middle } \\
65 \#\end{array}$ & $\begin{array}{c}\text { Middle } \\
75 \#\end{array}$ & $\begin{array}{c}\text { Lower } \\
135 \#\end{array}$ & $\begin{array}{c}\text { Lower } \\
145 \#\end{array}$ \\
\hline \multirow{10}{*}{$\begin{array}{l}\text { Periodic } \\
\text { pressure }\end{array}$} & \multirow{2}{*}{1} & Before & 8512.8 & 9012.2 & 9075.6 & 8756.6 & 8765.3 & 8858.1 \\
\hline & & After & 10625 & 10995.6 & 11662.8 & 11163.3 & 10894.3 & 11081.6 \\
\hline & \multirow{2}{*}{2} & Before & 9268.9 & 8749.8 & 10063.3 & 9461.62 & 8813.6 & 9254 \\
\hline & & After & 11921.6 & 10621.1 & 13000.6 & 11956.3 & 10738.8 & 11244.5 \\
\hline & \multirow{2}{*}{3} & Before & 11024.8 & 10328.8 & 10721.3 & 10404.1 & 10234.7 & 10122.8 \\
\hline & & After & 14456.5 & 13129.7 & 14386 & 14004.1 & 12418.8 & 12788.1 \\
\hline & \multirow{2}{*}{4} & Before & 10339.6 & 8750.6 & 10461.3 & 10003.1 & 10387.7 & 9529.5 \\
\hline & & After & 13819.5 & 10735 & 14462.7 & 13568.8 & 13110.6 & 12484.1 \\
\hline & \multirow{2}{*}{5} & Before & 10157.1 & 9287 & 10687.6 & 10525.7 & 9924.6 & 9540.7 \\
\hline & & After & 13780.8 & 12142.1 & 14712.6 & 14082.1 & 13123.8 & 12227.6 \\
\hline
\end{tabular}

\section{CONCLUSIONS}

(1) According to the mechanical test and XRD test results, the thick sandstone roof of working face 210106 has a high quartz content and strong siliceous cementation. In addition, the roof is stable and strong. The roof may not easily fall after mining the coal bed, and a large area of hanging arch exists. In the numerical simulation, the sandstone roof falls suddenly when the working face is advanced by $120 \mathrm{~m}$. A strong rock burst is produced upon the large-scale falling off of the roof, and the support is crushed, thereby forming a windstorm and gas transfinite.

(2) A mechanical analysis model of the roof in an island working face is constructed in accordance with thin plate theory. The results demonstrate that the fracture distance of the $16 \mathrm{~m}$ thick sandstone roof is $17.9 \mathrm{~m}$, and the support shall provide $16854.1 \mathrm{kN}$ of support resistances to maintain the structural stability of the roof. The advanced pre-splitting blasting of the $16 \mathrm{~m}$ thick sandstone roof shall be implemented, and the fracture distance shall be set to 15 $\mathrm{m}$ for the existing ZZ15000/24/50D support to satisfy the requirements of normal roof support.

(3) Deep-hole pre-splitting blasting is accomplished in working faces. Two groups of holes are set on each blasting section, with four holes in each group. According to the underground pressure monitoring data of the working face, the forced caving of thick sandstones relieves the influences of roof loads on the support and thus realizes the safe mining of the working face under the existing supporting equipment.

\section{Acknowledgment}

This work is financially supported by the National Natural Science Foundation of China (No.51674007) and State Key Laboratory for GeoMechanics. The authors gratefully acknowledge the assistance of the Huainan Mining Group, Anhui University of Science and 
Technology for providing access to the mine, data, and physical resources necessary to complete this work.

\section{REFERENCES}

[1] Wang, P., Jiang, F. X., Feng, Z. Q., \& Wang, D. Z (2011). Relationship between fracture of high-position thick and hard roof and mine quake forecast. Chinese Journal of Geotechnical Engineering, 33(4), 618-623.

[2] Guo, W. J. \& Liu, L. M.(1994). Study on the mining hazards and countermeasures in extra-thick and solid covering strata. The Chinese Journal of Geological Hazard and Control, 5(2), 37-42.

[3] Dou, L. M., He, Y., \& Zhang, W. D. (2003). Haxards of rock burst in island coal face and its control. Chinese Journal of Rock Mechanics and Engineering, 22(11), 1866-1869.

[4] Chen, R. H. \& Miao, X. X.(2005). Numerical simulation in mining pressure control of thick and strong stratum caving by water-infusion softening method. Chinese Journal of Rock Mechanics and Engineering, 24(13), 2266-2277.

[5] Pan, Y. S., Li, Z. H., \& Zhang, M. T.( 2003). Distribution, type, mechanism and prevention of rockbrust in China. Chinese Journal of Rock Mechanics and Engineering, 22(11), 1844-1851.

[6] Li, L. F., Wang, C., \& Duan, C. S. (2001). Advanced deep hole pre-blasting to deal with hard roof. Ground Pressure and Strata Control. (3), 72-74.

[7] Gou, X. Y., \& Chen, R. H. (2013). Support load analysis and mining pressure control in flat seam with thick and strong roof. Journal of Liaoning Technical University(Natural Science), 32(1), 24-28.

[8] Qian, M. G., Miao, X. X., \& Xu, J. L. (1996). Theoretical study of key stratum in grount control. Journal of China Coal Society, 21(3), 225-230.

[9] Lu, H. F., Yao, D. X., \& Liang, X. Y. (2013). Analytical solution of stress in a transversely isotropic floor rock mass under mining. Chinese Journal of Underground Space and Engineering, 9(5), 1050-1056.

[10] Hou, Z. J. (2016). Study on key stratum in shallow seam. Journal of China Coal Society, 24(4), 359-363.

[11] Liang, Y. P., Li, B., \& Yuan, Y. (2017). Moving type of key strata and its influence on ground pressure in fully mechanized mining face with large mining height. Journal of China Coal Society, 42( 6), 1380-1391.

[12] Yang, Q. B., Dai, X. G., \& Zou, Y. (2011). Fisher Discriminant Analysis for Predicting Dynamic Engineering Classification of Stope Roof Stability. Mining and Metallurgical Engineering, 31(2), 20-23.

[13] Xu, J. L., Zhu, W. B., \& Wang, X. Z. (2009). Classification of key strata structure of overlying strata in shallow coal seam. Journal of China Coal Society, 34(7), 865-870.

[14] Yuan, K. (2013). Split forming and parameters calculation principle of presplitting blasting. Blasting, 30(1), 58-62.

[15] Yang, T. H., Long, Y., \& Gu, W.B. (2000). Study on parameters selection and quality measures in smooth and presplitting blasting. Blasting, (1), 10-17.

[16] Wang, Y., Liang, B., \& Yuan, X. P. (2013). The application of deep hole pre-split blasting to gas improved extraction in high hydrogen sulphide mine. Journal of Chongqing University, 36(5), 101-106.

[17] Cai, F. \& Liu, Z. G. (2015). Numerical simulation and analysis of blasting process in rock using SPH-FEM coupling algorithm. Journal of Mining \& Safety Engineering, 32(5), 840-845.

\section{Contact information:}

\section{Baojie FU, PhD}

(Corresponding author)

1) Key Laboratory of Mining Coal Safety and Efficiently Constructed by Anhui Province and Ministry of Education, Anhui University of Science and Technology, Huainan, China, 232001,

2) Sch. of Mining \& Safety, Anhui University of Science and Technology, Huainan, China, 232001,

No.168 Taifeng Street, Huainan, Anhui Province,

E-mail: bjfu@aust.edu.cn

Min TU, PhD

1) Key Laboratory of Mining Coal Safety and Efficiently Constructed by Anhui Province and Ministry of Education, Anhui University of Science and Technology, Huainan, China, 232001,

2) Sch. of Mining \& Safety, Anhui University of Science and Technology, Huainan, China, 232001,

No.168 Taifeng Street, Huainan, Anhui Province,

E-mail: mtu@aust.edu.cn

Qingchong ZHAO, PhD

Sch. of Mining \& Safety, Anhui University of Science and Technology, Huainan, China, 232001,

No.168 Taifeng Street, Huainan, Anhui Province,

E-mail: 1142231702@qq.com 